\title{
Perspectivas de GÊNero nos Estudos da Religião: contribuições das ciências feministas
}

\author{
GENDER PERSPECTIVES IN RELIGIOUS STUDIES: \\ feminist sciences contributions
}

Ana Ester Pádua Freire*

\begin{abstract}
Resumo
Desde o século XX, o feminismo tem proposto diferentes abordagens ao fazer científico. As ressignificações que o feminismo imputa à ciência passam por uma crítica feminista das noções de sujeito e de objeto de estudo. Nesse sentido, seria possível pensar nas contribuições das ciências feministas ao estudo do fenômeno religioso, afinal, o gênero feminino presente nas religiões impulsiona mudanças, pois as mulheres estão abertas aos novos referenciais que a história e a vida sugerem. Apresentando possíveis relações entre o feminismo e a ciência, o presente artigo propõe uma epistemologia feminista que contribua para o estudo das Ciências da Religião, pois ao lançarem mão do referencial teórico feminista, essas resgatam as mulheres de sua invisibilidade, interpretando-as a partir do concreto de sua existência.
\end{abstract}

Palavras-chave: Epistemologia feminista. Ciência feminista da religião. Gênero.

\begin{abstract}
Since the twentieth century, feminism has proposed different approaches to scientific making. The reassignments feminism imputes to science pass through a feminist critique of the notions of subject and object of study. In this sense, it would be possible to think about the contributions of the feminist sciences to the study of the religious phenomenon, after all, the feminine gender present in the religions drives changes, since women are open to the new references that history and life suggest. Presenting possible relations between feminism and science, the present article proposes a feminist epistemology that contributes to the study of the Religious Studies, because when they use the feminist theoretical reference, they rescue the women from their invisibility, interpreting them from the of its existence.
\end{abstract}

Keywords: Feminist epistemology. Feminist religious studies. Gender.

\section{INTRODUÇÃO}

O estudo das religiões lança mão de um instrumental científico plural, podendo se aproximar de seu objeto de estudo a partir de metodologias diversas, ou seja, o trabalho teórico-metodológico em Ciências da Religião é fruto da consideração de disciplinas auxiliares (FERREIRA; SENRA, 2013). Pode-se afirmar que a interdisciplinaridade permeia as Ciências da Religião, pois essas vêm se

\footnotetext{
* Mestra em Ciências da Religião pela Pontifícia Universidade Católica de Minas Gerais. Doutoranda do Programa de Pós-graduação em Ciências da Religião na mesma universidade. Email: anaester99@yahoo.com.br
} 
estabelecendo no Brasil como campo disciplinar propício a contribuições de outras áreas de pesquisa, como a antropologia, a sociologia, a filosofia, dentre tantas outras.

Assim sendo, faz-se possível um diálogo das Ciências da Religião com o feminismo, na busca por compreender em que medida as abordagens feministas podem colaborar com o estudo das religiões. Desde o século XX, o feminismo tem proposto diferentes abordagens ao fazer científico. Ainda que não sejam simpatizantes ou adeptos ao feminismo, cientistas têm sido impactados pela presença da mulher na ciência não somente como cientista, mas também como objeto da ciência. Partindo desse princípio, consideram-se as Ciências da Religião campo favorável para que a perspectiva feminista apresente suas contribuições.

Como reflete Ivone Gebara (1997), o gênero feminino presente nas religiões impulsiona mudanças, pois as mulheres estão abertas aos novos referenciais que a história e a vida sugerem.

\section{FEMINISMO E CIÊNCIA}

No levantamento das contribuições das abordagens feministas para o estudo do fenômeno religioso, faz-se necessária uma incursão sobre a relação entre o feminismo e a ciência. Para tanto, parte-se da afirmação de que a crítica feminista radicalmente impactou a ciência. As ressignificações que o feminismo imputa à ciência passam por uma crítica feminista das noções de sujeito e de objeto de estudo, pois, como aponta Londa Schiebinger (2001), a ciência, por ser uma atividade humana, deve servir a todos, inclusive a mulheres e a feministas.

A crítica feminista, no uso do gênero como categoria de análise, reflete sobre as relações que se dão entre homens e mulheres na história. Essas relações marcam o fazer científico, que se apresenta majoritariamente masculino. A entrada das mulheres na ciência alterou não somente a maneira de se fazer ciência, como também, o que se passou a ser pesquisado. 


\subsection{A mulher e a ciência}

Ao se pensar sobre a ciência, é possível afirmar, como Attico Chassot (2014), que não somente a ciência, mas toda a produção intelectual, ainda que na contemporaneidade, é majoritariamente masculina. Chassot levanta, a partir da história recente, perguntas sobre esse caráter masculino da ciência.

Sobre a quase ausência de mulheres na História da Ciência, não deixa de ser significativo que, ainda nas primeiras décadas do século 20, a ciência estava culturalmente definida, como uma carreira imprópria para a mulher, da mesma maneira que, ainda na segunda metade do século 20, se dizia quais eram as profissões de homens e quais as de mulheres. Por que, na aurora do terceiro milênio, há mais alunas em cursos de Pedagogia? Ou mais alunos em cursos de Geologia? Não continuamos ainda demarcando quais são os espaços públicos ou quais as profissões dos homens e quais das mulheres? (CHASSOT, 2014, p. 1).

No mesmo sentido crítico, Cecilia Maria Bacellar Sardenberg (2007) afirma que, historicamente, a ciência moderna objetificou as mulheres, negando a elas a capacidade e autoridade do saber, produzindo conhecimentos que não atendem aos seus interesses emancipatórios. Essa realidade de cerceamento da mulher no âmbito da ciência, para Schiebinger (2001), dá-se porque a ciência moderna é um produto de centenas de anos de exclusão das mulheres. Por isso, “o processo de trazer mulheres para a ciência exigiu, e vai continuar a exigir, profundas mudanças estruturais na cultura, métodos e conteúdo da ciência” (SCHIEBINGER, 2001, p. 37).

Apesar das críticas levantadas, que apontam para uma exclusão das mulheres do ambiente científico, é possível afirmar que, desde o século XX, o feminismo tem permeado os saberes, trazendo consigo diferentes abordagens ao fazer científico. Segundo Evelyn Fox Keller (2006), os atravessamentos feministas caminham na direção de um maior acesso das mulheres à ciência e do surgimento da crítica feminista da ciência.

Para Schiebinger (2001), o feminismo tem, pelo menos, duas maneiras de contribuir com o fazer científico: pela presença da mulher fazendo ciência e pela mulher como objeto de estudo. Em concordância, Lourdes Bandeira (2008, p. 219) afirma que "o pensamento feminista introduziu novos sujeitos, como atores e novos sujeitos como objetos de pesquisa”, alterando, portanto, a agenda da ciência. 
Entretanto, como explica Maria José F. Rosado-Nunes (1996), a proposta feminista não é simplesmente de acrescentar as mulheres aos estudos já existentes, mas "reconstruir o instrumental de análise da realidade pela incorporação do gênero [...] como categoria analítica” (ROSADO-NUNES, 1996, p. 99). Cabe, então, uma investigação sobre a relação entre o feminismo e a ciência.

\section{$2.2 \mathrm{O}$ feminismo e a ciência}

Com relação ao impacto do feminismo na ciência, para Schiebinger (2001), as contribuições estão para além da presença da mulher seja como cientista ou como objeto da ciência.

As diferenças historicamente elaboradas entre mulheres e homens não podem servir como base epistemológica para novas teorias e práticas nas ciências. [...] As metas feministas na ciência não serão realizadas através da invocação de princípios dominados por clichês tirados de um mítico "feminino perdido". [...] É tempo de voltar-se para instrumentos de análise pelos quais a pesquisa científica possa ser desenvolvida, bem como criticada em linhas feministas. (SCHIEBINGER, 2001, p. $31)$.

Schiebinger (2001) destaca que o que mudou a ciência, não foi apenas a presença da mulher, mas sim o feminismo. Feminismo que pode ser praticado tanto por homens quanto por mulheres, pois possui um pano de fundo político. Branca Moreira Alves e Jacqueline Pitanguy afirmam que

o feminismo se constrói a partir das resistências, derrotas e conquistas que compõe a História da Mulher e se coloca como um movimento vivo, cujas lutas e estratégias estão em permanente processo de re-criação. Na busca da superação das relações hierárquicas entre homens e mulheres, alinha-se a todos os movimentos que lutam contra a discriminação em suas diferentes formas. (ALVES; PITANGUY, 1982, p. 74).

Para Alves e Pitanguy (1982), o feminismo é um movimento vivo e dinâmico de resistência contra as desigualdades que se estabelecem nas relações entre homens e mulheres. Inúmeras são as possibilidades de uma compreensão histórica do movimento feminista, os recortes podem ser geográficos, políticos etc. A história do feminismo revela que ele não é algo estático ou unívoco. Segundo Alzira Munhoz (2008, p. 22), "rupturas, saltos, reconfigurações, sempre enriqueceram a caminhada 
feminista, de tal forma que o feminismo - ou os feminismos - vem forjando um processo de profundas mudanças socioculturais".

Nesse sentido, para Anthony Giddens (2005, p. 102), “as drásticas mudanças iniciadas pelo movimento feminista, nos anos de 1970, inspiraram novos esforços para entender como se criam, se sustentam e se transformam os padrões e as desigualdades de gênero em nossas sociedades”. Por isso, é impossível usar os aportes do feminismo sem a preocupação política que o conceito exige. Para Munhoz, o feminismo é a expressão da "tomada de consciência coletiva pelas mulheres de sua condição histórica de opressão sim, mas muito mais ainda da sua resistência ativa e organizada para modificar essa situação e se tornarem sujeitos políticos de transformação" (MUNHOZ, 2008, p. 24-25).

O feminismo, como conceito dinâmico, é uma ação e compromisso éticopolítico das mulheres a partir de sua condição de gênero (MUNHOZ, 2008). O feminismo lança mão do conceito de gênero como uma categoria de análise baseada nas relações que se estabelecem socialmente a partir das diferenças entre os sexos (SCOTT, 1989).

Compreendido o feminismo como movimento político, é possível afirmar, segundo Sardenberg (2007), que as práticas científicas feministas fundamentam-se, assumidamente, em uma práxis política. Política essa, que tem como projeto a transformação das relações de gênero, como explica:

pensar em uma ciência feminista - ou em qualquer outra possibilidade de ciência politizada - requer, como primeiro passo, a desconstrução dos pressupostos iluministas quanto à relação entre neutralidade, objetividade e conhecimento científico. Requer, portanto, a construção de uma epistemologia feminista - de uma teoria crítica feminista sobre o conhecimento -, que possa autorizar e fundamentar esse saber que se quer politizado. (SARDENBERG, 2007, p. 3).

A crítica de Sardenberg (2007) recai sobre os princípios da neutralidade e da objetividade na construção do conhecimento científico. A crítica feminista, muitas vezes, apresenta-se contrária à objetividade e à neutralidade científicas positivistas, assim como a proposta de "destruição do positivismo lógico", de Edgar Morin (2008).

Morin (2008) vê na complexidade científica, não um inimigo a ser eliminado, mas um desafio a ser enfatizado. Para o autor, o progresso das certezas científicas não caminha na direção de uma grande certeza. Segundo Morin (2008, p. 21), “a verdade objetiva da ciência escapa a todo olhar científico, visto que ela é esse próprio olhar”, 
garantindo à ciência a característica de ser uma atividade construída com todos os ingredientes da atividade humana.

Em uma destruição do positivismo lógico, Morin (2008) conclui que a ciência é "impura”.

A vontade de encontrar uma demarcação nítida e clara da ciência pura, de fazer uma decantação, digamos do científico e do não-científico, é uma ideia errônea e diria também uma ideia maníaca. [...] O notável é que a ciência não só contém postulados e themata ${ }^{1}$ não científicos, mas que estes são necessários para a constituição do próprio saber científico, isto é, que é preciso a não-cientificidade para produzir a cientificidade, do mesmo modo que, sem cessar, produzimos vida com a não-vida. (MORIN, 2008, p. 59).

A "impureza" científica apontada por Morin (2008) não descaracteriza a ciência, pelo contrário, aponta para um "outro" fazer científico, livre do monismo epistemológico e da neutralidade.

Com relação à neutralidade científica, duas questões merecem destaque. A primeira diz respeito à neutralidade da ciência em relação às questões de gênero. Para Schiebinger (2001), o feminismo refuta a ideia de que a ciência é neutra em relação às questões de gênero. Ao contrário, revela que os valores geralmente atribuídos às mulheres têm sido excluídos do saber científico e, também, que as desigualdades entre homens e mulheres foram incorporadas à produção e à estrutura do conhecimento. Para Marjorie L. DeVault (1996), o fazer científico aponta para a omissão e para a distorção da experiência feminina, pois tende a universalizar a experiência masculina.

A outra questão diz respeito à neutralidade científica dada entre a relação do cientista e seu objeto de estudo. Sobre esta, Ana María Bach afirma que:

não deveríamos falar sobre conhecimento comum e conhecimento crítico, já que nas investigações científicas quem investiga não pode deixar de lado seu conhecimento cotidiano. Não haveria uma linha definida entre uma forma de saber e outra, porém o conhecimento se daria em um contínuo que vai do mais subjetivo ao mais objetivo. (BACH, 2010, p. 8, tradução nossa) ${ }^{2}$.

${ }^{1}$ Themata, do grego thema, singular e themata, plural. Para Morin (2008, p. 44), themata "é uma preocupação fundamental, estável, largamente difundida e que não se pode reduzir diretamente à observação ou ao cálculo analítico do qual não deriva”. Ou seja, serve para instigar a pesquisadora e o pesquisador. Termo usado por Holton em HOLTON, G. L'imagination scientifique. Paris: Gallimard, 1981.

${ }^{2}$ No deberíamos hablar de conocimiento ordinario y conocimiento crítico, ya que en las investigaciones científicas quien investiga no puede dejar de lado su conocimiento cotidiano. 
Para Bandeira (2008), a crítica feminista coloca em suspeição as premissas conceituais e hipóteses usuais que estruturam a lógica da investigação positivista. Pesa sobre a busca pelo objetivismo científico, a crítica feminista, pois, como explica Sardenberg (2007, p. 5), “as pensadoras feministas vêm de há muito colocando em questionamento os parâmetros científicos definidores de quem pode ou não ser sujeito do conhecimento, do que pode consistir como conhecimento, ou mesmo o que pode ser conhecido”. Entretanto, é importante destacar que colocar sob suspeita os paradigmas da objetividade e da neutralidade não quer dizer descartá-los.

A crítica feminista aponta para a importância daquele que faz ciência. Tomando como princípio as questões levantadas sobre a neutralidade científica, Schiebinger esclarece que não deveria ser proposta, a partir do feminismo, "uma ciência 'feminista' especial, esotérica, mas sim, uma capaz de incorporar uma consciência crítica de gênero na formação básica de jovens cientistas e no mundo rotineiro da ciência” (SCHIEBINGER, 2001, p. 31).

Para Sardenberg (2007), o feminismo relaciona-se com a ciência, pelo menos, de duas maneiras. A primeira diz respeito aos avanços teórico-metodológicos no interior do próprio pensamento feminista com a construção e teorização em torno das relações de gênero. A segunda diz respeito ao impacto da crítica feminista, contribuindo para a desmistificação da ciência.

Podemos dizer que, de um modo geral, a crítica feminista historiciza a ciência, voltando-se para a análise de como as categorias de gênero têm historicamente influenciado os conceitos de conhecimento, sujeito cognoscente, justificativas e práticas de investigação ditas científicas. (SARDENBERG, 2007, p. 10).

Cabe, então, à epistemologia feminista, segundo Sardenberg (2007), propor princípios, conceitos e práticas que possam superar as limitações de outras estratégias epistemológicas, no sentido de atender aos interesses sociais, políticos e cognitivos das mulheres e de outros grupos historicamente subordinados. Sendo assim, pode-se afirmar que o feminismo atua no campo da ciência, "no sentido de provocar refinamentos, correções, rejeições ou mesmo compartilhando assertivas e modelos formulados por outras semelhantes forças” (SARDENBERG, 2007, p. 13). Como explica Bandeira (2008, p. 211),

No habría una línea definida entre una forma de saber y otra sino que el conocimiento se daría en un continuo que va de lo más subjetivo a lo más objetivo. 
o desafio da crítica feminista foi, precisamente, o de contrapor-se aos hegemônicos eixos epistemológicos e conceituais - categorias, conceitos e métodos - para não reproduzir como espelho distorcido as próprias categorias do sistema de dominação científica que tomou como objeto da crítica.

Segundo Ivone Gebara (2010), existem elementos e tarefas, que são fundamentais a todo conhecimento. A primeira tarefa é a crítica ao universalismo das ciências. A pretensão de um homem universal a serviço da ciência já não seria possível a partir de uma antropologia feminista, que não somente valoriza a mulher, mas a mulher singular, revestida de suas particularidades.

Outra tarefa é a tentativa de superação do idealismo masculino presente nas elaborações filosóficas, relegando a mulher à natureza e o homem, à cultura. Gebara (2010) critica o dualismo mulher/natureza, homem/cultura tão próprio à ciência positivista. Para a autora, é papel do feminismo na ciência introduzir o relativismo cultural, isto é, afirmar as diferentes maneiras de interpretar o mundo como necessárias à vida do planeta.

Segundo Gebara (2010), outra tarefa do conhecimento é a introdução de uma ética plural em que os sujeitos reflitam a partir de sua realidade própria. Esta questão é chave para o feminismo proposto por Gebara, que não somente busca superar o universalismo, como empodera o sujeito a partir de sua realidade, valorizando assim o mundo da vida. Assim, a autora propõe a valorização da diversidade e da diferença e a valorização do cotidiano de mulheres e homens como aproximação primeira para qualquer pensamento chamado científico. Deve ser característica do conhecimento, a interdependência entre todas as coisas e todos os níveis de nossa existência, e, em consequência, a transdiciplinaridade e complexidade das ciências. As tarefas apontadas por Gebara (2010) revelam sua posição crítica em relação à ciência universalista e sua defesa à ciência que se propõe particular e que é baseada em relações humanas mais justas.

Diante do exposto, é possível afirmar que a crítica feminista coloca sob suspeita aportes da ciência, questionando critérios como objetividade e neutralidade. Todavia, não os descartando, mas sim os ressignificando a partir de um sujeito congnoscente que não se pretenda universal. 


\section{EPISTEMOLOGIA FEMINISTA}

Destaca-se, o importante papel para a Ciência Feminista, do sujeito cognoscente e suas particularidades, pois ele é modificado pelas perspectivas feministas do conhecimento. Sua individualidade é ressaltada, culminando em uma pluralidade epistemológica feminista.

Não existe uma epistemologia feminista única. O que existe é uma superabundância de ideias, aproximações e argumentos que têm em comum somente o comprometimento de seus autores com a exposição e a reversão da derrogação das mulheres e do preconceito de gênero das fórmulas tradicionais. (LONGINO, 2008, p. 513).

Partindo da compreensão de Longino (2008) sobre a pluralidade epistemológica feminista, propõe-se uma discussão a partir de feministas que ousaram pensar sobre uma teoria feminista do conhecimento a partir de sua prática.

\subsection{Pluralidade epistemológica feminista}

A crítica feminista questiona os aportes usados pela ciência, que acabam por corroborar com uma ciência universalizante, branca, androcêntrica e ocidental. A tarefa implicada à crítica feminista radical da ciência é, segundo Keller (1982), histórica e transformadora. A autora afirma que "em um esforço histórico, as feministas podem trazer toda uma nova gama de sensibilidades, levando a uma nova consciência igualitária das latentes possibilidades do projeto científico" (KELLER, 1982, p. 602, tradução nossa) 3 .

Nesse esforço transformador, são lançadas as bases para uma Ciência Feminista, que busca reconstruir o modo pelo qual algo se torna conhecido. Segundo Sardenberg (2007, p. 10), "uma epistemologia feminista deve constituir-se, necessariamente, através de um processo de mão dupla, ou seja, de um processo tanto de desconstrução como de construção”.

Nessa mesma perspectiva, segundo Rago (1998), o projeto feminista de ciência, ou a epistemologia feminista, é o campo conceitual a partir do qual o

3 In the historical effort, feminists can bring a whole new range of sensitivities, leading to an equally new consciousness of the potentialities lying latent in the scientific project.

INTERAÇõES, Belo Horizonte, Brasil, v. 13. n. 23, p.115-131, jan./jul.2018

ISSN 1983-2478 
conhecimento científico é produzido. Para a autora, a epistemologia feminista é o "contradiscurso" ou "nova linguagem", pois é o conhecimento sendo produzido a partir de outras "vozes”, ou seja, de outros sujeitos.

Ao pensar a partir de diferentes sujeitos, a epistemologia feminista questiona as relações de poder outrora estabelecidas nas formas de conhecimento vigentes. Segundo Diana Maffia (2007, tradução nossa) 4,

os achados epistemológicos mais fortes do feminismo encontram-se na ligação que foi feita entre "conhecimento" e "poder". Não apenas no sentido óbvio de que o acesso ao conhecimento implica o aumento do poder, mas de modo mais controverso através do reconhecimento de que a legitimação das pretensões do conhecimento está intimamente ligada a redes de dominação e de exclusão.

A crítica feminista evidencia as relações de poder constitutivas da produção dos saberes. A epistemologia feminista, então, busca desarticular a aparente neutralidade de quem produz ciência, revelando os interesses que estão por trás das teorias científicas. Essa análise é feita a partir, por exemplo, da linguagem da ciência. Para Maffia (2007), a linguagem apropria-se de metáforas sexuais, que revelam relações de poder e relações de gênero opressivas, colocando a ciência a serviço do controle social.

Ao desarticular as metáforas usadas pelos cientistas, são descobertas as analogias que revelam não somente a suposição acrítica, mas também o reforço de certos valores sociais vigentes. Quando estes valores implicam relações de gênero opressivas, a ciência põe-se a serviço do controle social. (MAFFIA, 2007, tradução nossa) 5 .

Nesse sentido, a epistemologia feminista pressupõe-se contrária à posição hegemônica do conhecimento produzido. A crítica feminista à ciência busca revelar não apenas como as categorias de gênero têm se inserido no vértice da ciência, mas, sobretudo, o androcentrismo desse sujeito branco e ocidental.

\footnotetext{
4 Los hallazgos epistemológicos más fuertes del feminismo reposan en la conexión que se ha hecho entre 'conocimiento' y 'poder'. No simplemente en el sentido obvio de que el acceso al conocimiento entraña aumento de poder, sino de modo más controvertido a través del reconocimiento de que la legitimación de las pretensiones de conocimiento está íntimamente ligada con redes de dominación y de exclusión.

$5 \mathrm{Al}$ desarticular las metáforas usadas por científicos, quedan de manifiesto las analogías que revelan no sólo la asunción acrítica sino incluso el refuerzo de ciertos valores sociales predominantes. Cuando esos valores implican relaciones opresivas entre los géneros, la ciencia se pone al servicio del control social.
} 
A epistemologia feminista, segundo Rago (1998), enfatiza a historicidade dos conceitos e a coexistência de temporalidades. "Os estudos feministas inovam na maneira como trabalham com as multiplicidades temporais, descartando a ideia de linha evolutiva inerente aos processos históricos" (RAGO, 1998, p. 12), reconhecendo, assim, a particularidade do modo de pensamento, abandonando a pretensão de ser uma única possibilidade de interpretação.

A relação com a qual a epistemologia feminista relaciona-se com a pluralidade de perspectivas dá-se a partir do uso da categoria de gênero como categoria analítica. O gênero torna-se uma categoria que sustenta esse rico "edifício” epistemológico.

\subsection{Epistemologia feminista e a categoria analítica de gênero}

Segundo Joan Scott (1989), gênero refere-se à organização social da relação entre os sexos. Para ela, o conceito baseado na questão da "relação" é um desafio teórico, pois

exige a análise não somente da relação entre experiências masculinas e femininas no passado, mas também a ligação entre a história do passado e as práticas históricas atuais. Como o gênero funciona nas relações sociais humanas? Como o gênero dá sentido à organização e à percepção do conhecimento histórico? As respostas dependem do gênero como categoria de análise. (SCOTT, 1989, p. 1055, tradução nossa) ${ }^{6}$.

O gênero como categoria de análise, em seu uso historiográfico, como o proposto por Scott (1989), propõe-se a rever a história das relações entre homens e mulheres na busca por compreender as relações sociais que são estabelecidas entre os dois. Nessa perspectiva, o gênero une-se a outras categorias de análise não se sobrepondo, mas somando, em um esforço analítico para compreender como se dão as relações entre homens e mulheres.

\footnotetext{
${ }^{6}$ it requires analysis not only of the relationship between male and female experience in the past but also of the connection between past history and current historical practice. How does gender work in human social relationships? How does gender give meaning to the organization and perception of historical knowledge? The answers depend on gender as an analytic category.
} 
Segundo Scott (1989, p. 1067, tradução nossa) 7, "gênero é um elemento constitutivo das relações sociais baseado nas diferenças percebidas entre os sexos, e o gênero é uma forma primeira de significar as relações de poder”. Essa definição do conceito de gênero aponta para seu aspecto crítico diante das relações de poder que se estabelecem baseadas nas diferenças percebidas entre os sexos.

Nesse enfoque, para Miriam Grossi gênero é "uma categoria usada para pensar as relações sociais que envolvem homens e mulheres, relações historicamente determinadas e expressas pelos diferentes discursos sociais sobre a diferença sexual" (GROSSI, 2014, p. 5). Pode-se dizer, então, que gênero é mutável, pois é social, cultural e historicamente determinado.

Gênero diz respeito, então, a construções sociais, culturais e históricas que culminam em hierarquias que se estabelecem a partir da binarização dos sexos. Para Gayle Rubin (1986) seria impossível compreender a mulher apenas a partir de seu sexo, por isso a importância de uma teoria que a compreenda a partir das relações que se estabelecem entre o sexo e o gênero. Neste sentido, Giddens (2005) explica que as diferenças entre os gêneros podem ser entendidas a partir da socialização do gênero, com a aprendizagem de papeis de gênero $^{8}$.

Essa abordagem, que parte da socialização, faz distinção entre sexo biológico 9 e gênero social - uma criança nasce com o primeiro e desenvolve o segundo (GIDDENS, 2005). Ou seja, “as diferenças de gênero não são biologicamente determinadas, mas sim culturalmente produzidas" (GIDDENS, 2005, p. 105). Compreendem-se aqui, as identidades de gênero como sendo resultados de influências sociais.

Grossi (2014) resume assim a questão,

\footnotetext{
7 gender is a constitutive element of social relationships based on perceived differences between the sexes, and gender is a primary way of signifying relationships of power.

${ }^{8}$ Segundo Miriam Grossi (2014), papéis de gênero são representações de um personagem. Segundo a autora, tudo aquilo que é associado ao sexo biológico fêmea ou macho em determinada cultura é considerado papel de gênero. Estes papéis mudam de uma cultura para outra.

9 É importante ressaltar que existem teorias que não compreendem o sexo como um dado biológico, mas também como uma construção social. Segundo elas, "o corpo humano e a biologia não estão 'dados', mas estão sujeitos ao agenciamento humano e às escolhas pessoais no interior de diferentes contextos sociais" (GIDDENS, 2005, p. 106). Por exemplo, as teses de performatividade de gênero, de Judith Butler.
} 
de uma forma simplificada, diria que sexo é uma categoria que ilustra a diferença biológica entre homens e mulheres; que gênero é um conceito que remete à construção cultural coletiva dos atributos de masculinidade e feminilidade. (GROSSI, 2014, p. 12).

Compreendido, então, o gênero como uma categoria analítica criada a partir das abordagens feministas, pode-se afirmar, como Sardenberg (2007), que a Ciência Feminista é "um saber alavancado em uma perspectiva crítica feminista de gênero" (SARDENBERG, 2007, p. 2). Como explica Scott (1989, p. 1066, tradução nossa) ${ }^{10}$,

do lado da crítica da ciência desenvolvida pelas ciências humanas e da crítica do empiricismo e do humanismo que desenvolvem os pós-estruturalistas, as feministas não somente começaram a encontrar uma via teórica própria, como elas também encontraram aliados cientistas e políticos. É nesse espaço que nós devemos articular o gênero como uma categoria de análise.

Para Scott (1989), o gênero é uma categoria de análise que deve ser usada na ciência, refazendo-a e ressignificando-a. Nessa mesma perspectiva, Rago (1998) explica que a categoria de gênero "desnaturaliza as identidades sexuais e postula a dimensão relacional do movimento constitutivo das diferenças sexuais" (RAGO, 1998, p. 6). Sendo assim, gênero como categoria de análise rompe com o enquadramento conceitual normativo.

Além disso, gênero, como categoria de análise, propõe novos temas, novos objetos e novas questões à ciência. Como, por exemplo, bruxaria, prostituição, aborto, parto, maternidade, saúde, sexualidade (RAGO, 1998).

Feministas assumidas ou não, as mulheres forçam a inclusão dos temas que falam de si, que contam sua própria história e de suas antepassadas e que permitem entender as origens de muitas crenças e valores, de muitas práticas sociais frequentemente opressivas e de inúmeras formas de desclassificação e estigmatização. De certo modo, o passado já não nos dizia e precisava ser re-interrogado a partir de novos olhares e problematizações, através de outras categorias interpretativas, criadas fora da estrutura falocêntrica especular. (RAGO, 1998, p. 13)

A pluralidade epistemológica feminista, aqui levantada, reverbera no impacto das abordagens feministas para as Ciências da Religião. O estudo sobre as religiões no Brasil lança mão de um instrumental científico plural. O uso do arcabouço

${ }^{10}$ on the side of the critique of science developed by the humanities, and of empiricism and humanism by post-structuralists, feminists have not only begun to find a theoretical voice of their own but have found scholarly and political allies as well. It is within this space that we must articulate gender as an analytic category. 
interdisciplinar pelas Ciências da Religião aponta para sua pluralidade epistemológica. Amauri Carlos Ferreira e Flávio Augusto Senra Ribeiro (2012) ao tratarem sobre as Ciências da Religião a partir de uma perspectiva interdisciplinar, explicam que

a questão religiosa deveria ocupar o interesse central na investigação. A sociologia, a antropologia, a psicologia ou a história podem se ocupar da religião apenas como um interesse secundário. Porém, assumida a perspectiva interdisciplinar das Ciências da religião, cada disciplina passa a ser entendida como uma específica contribuição nos estudos sobre as religiões. (FERREIRA; RIBEIRO, 2012, p. 257).

As Ciências da Religião recebem contribuições de outros campos disciplinares, também em uma perspectiva epistemológica plural, entretanto nunca perdendo de vista o interesse central de sua investigação: o fenômeno religioso. Esse é o centro do caráter interdisciplinar das Ciências da Religião.

Infere-se sobre as Ciências da Religião, a partir de Ferreira e Ribeiro (2012, p. 253), que "a realidade atual está fadada a assumir a constituição plural da realidade e terá de enfrentá-la na pluralidade das compreensões disponíveis e na perspectiva relacional orientada pela soma de diferentes perspectivas disciplinares”. O caráter plural das Ciências da Religião, portanto, aponta para uma interdisciplinaridade propícia a diferentes epistemologias. Sendo assim, a epistemologia feminista é mais uma possível proposta de produção do conhecimento para as Ciências da Religião.

\section{CONSIDERAÇÕES FINAIS}

O cotidiano torna-se o ponto de partida para o método fenomenológico feminista, o lócus privilegiado para a construção teórica (MUSSKOPF, 2012). O cotidiano permite o entrelaçamento de múltiplas experiências e, assim, a busca pelo sentido diante da pluralidade que caracteriza toda a existência. As Ciências da Religião, ao lançarem mão do referencial teórico feminista, resgatam as mulheres de sua invisibilidade, interpretando-as a partir do concreto de sua existência.

Nesse rico contexto dos aportes lançados pela Ciência Feminista, as Ciências da Religião podem se tornar, ainda mais, um espaço de pesquisa qualificada sobre as religiões, a vida espiritual e suas complexidades. Em se tratando de uma ciência em 
formação no Brasil, as Ciências da Religião possuem uma epistemologia plural e interdisciplinar apta ao diálogo com os aportes feministas de pesquisa.

A introdução de elementos teórico-metodológicos oriundos do feminismo para a análise das religiões implica em "interrogar a realidade religiosa do ponto de vista das diferenças colocadas pelas relações sociais estabelecidas entre os sexos" (ROSADO-NUNES, 2001). O que eu aqui é nomeado de Ciência Feminista da Religião ocupa-se em produzir conhecimento a partir das vozes das mulheres, em conhecer os ritos através das práticas ocultadas das mulheres, em compreender a ética religiosa a partir das relações estabelecidas entre as mulheres. Compreensão marcada pela reciprocidade e interdependência das mulheres, que muitas vezes foram esquecidas pela história, pela ciência e pelas religiões.

A Ciência Feminista da Religião é um espaço de tessitura de sentidos para a vida, desconstruindo o instrumental teórico positivista em busca da revisão das posições de poder, conteúdos e simbologias que excluíram ou diminuíram as mulheres considerando-as como cidadãs de segunda categoria. Tecendo sentidos, as Ciências da Religião em uma perspectiva feminista promovem a superação dos dualismos e das hierarquias patriarcais, buscando novas respostas para as novas perguntas que a categoria analítica de gênero propõe. Exigindo, assim, uma visibilidade das mulheres na história das religiões, que corresponda à realidade dos fatos a partir da concretude da vida.

\section{REFERÊNCIAS}

ALVES, Branca Moreira; PITANGUY, Jacqueline. O que é feminismo. São Paulo: Brasiliense, 1982.

BACH, Ana María. El rescate del conocimiento. Revista del Centro de Estudios Históricos e Interdisciplinario Sobre las Mujeres Facultad de Filosofía y Letras Universidad Nacional de Tucumán, Tucumán, ano 6, nº 6, 2010. Disponível em: <http://www.filo.unt.edu.ar/rev/temas/t6/ t6_web_art_ambach_elrescate.pdf $>$. Acesso em: 2 jul. 2014.

BANDEIRA, Lourdes. A contribuição da crítica feminista à ciência. Estudos Feministas, Florianópolis, v. 16, n. 1, jan./apr. 2008. Disponível em: <http:// www.scielo.br/scielo.php?pid=S0104-026X2008000100020\&script $=$ sci arttext>. Acesso em: 7 jul. 2014. 
CHASSOT, Attico. A Ciência é masculina? É, sim senhora!... Programa de Pós Graduação em Educação - UNISINOS - Brasil. Disponível em:

$<$ http://www.cimm.ucr.ac.cr/ciaem/memorias/xii_ciaem/124_ciencia_ masculina.pdf $>$. Acesso em: 2 jul. 2014.

DEVAULT, Marjorie L. Talking back to sociology: distinctive contributions of feminist methodology. Annual Review of Sociology, v. 22: 29-50, 1996.

Disponível em: <http://www.annualreviews.org/doi/abs/10.1146/ annurev.soc.22.1.29>. Acesso em: 20 jun. 2013.

FERREIRA, Amauri Carlos; RIBEIRO, Flávio Augusto Senra. Tendência interdisciplinar das ciências da religião no Brasil. O debate epistemológico em torno da interdisciplinaridade e o paralelo com a constituição da área no país. Numen, Juiz de Fora, v. 15, n. 2, p. 249-269, dez 2012. Disponível em: <http://ufjf.emnuvens.com.br/numen/article/viewFile/1729/1446>. Acesso em: 16 jun. 2014 .

GEBARA, Ivone. Teologia Ecofeminista. São Paulo: Olho d’Água, 1997.

GEBARA, Ivone. Vulnerabilidade, justiça e feminismos. São Bernardo do Campo: Nhanduti, 2010.

GIDDENS, Anthony. Gênero e sexualidade. In: Sociologia. Porto Alegre: Artmed Editora, 2005.

GROSSI, Miriam Pillar. Identidade de gênero e sexualidade. Disponível em: <http://www.direito.mppr.mp.br/arquivos/File/GROSSIMiriam.pdf>. Acesso em: 10 mar. 2014. p.1-14.

KELLER, Evelyn Fox. Qual foi o impacto do feminismo na ciência? Cadernos Pagu, Campinas, v. 27, p. 13-34, jul. dez., 2006. Disponível em: <

http://www.scielo.br/pdf/cpa/n27/32137.pdf>. Acesso em: 20 jun. 2013.

KELLER, Evelyn Fox. Feminism and Science. In: Signs. Vol. 7, No. 3, Feminist. Theory (Spring, 1982), pp. 589-602. Published by: The University of Chicago Press. Disponível em: < http://www.jstor.org/stable/3173856/>. Acesso em: 13 jan. 2015.

LONGINO, Helen E. Epistemologia feminista. In: GRECO, John; SOSA, Ernest (Orgs.). Compêndio de epistemologia. São Paulo: Edições Loyola, 2008.

MAFFIA, Diana. Epistemología feminista: La subversión semiótica de las mujeres en la ciencia.Revista Venezolana de Estudios de la Mujer, Caracas, v. 12, n. 28, jun. 2007. Disponível em: < http://www.scielo.org. ve/scielo.php?pid=S1316-37012007000100005\&script=sci_arttext $>$. Acesso em: 13 jan. 2015 .

MORIN, Edgar. Ciência com consciência. Rio de Janeiro: Bertrand Brasil, 2008. 
MUNHOZ, Alzira. Feminismo e evangelização: uma abordagem históricoteológica à luz do conceito de evangelização das diretrizes gerais da ação evangelizadora na igreja no Brasil. 2008. Tese (Doutorado) - Faculdade Jesuíta de Filosofia e Teologia, Teologia Sistemática, Belo Horizonte.

MUSSKOPF, André Sidnei. Via(da)gens teológicas: itinerários para uma teologia queer no Brasil. São Paulo: Fonte Editorial, 2012.

RAGO, Margareth. Epistemologia feminista, gênero e história. In: PEDRO, Joana; GROSSI, Miriam (Orgs.). Masculino, feminino, plural. Florianópolis: Ed. Mulheres, 1998. Disponível em: <http://projenpq.mpbnet. com.br/textos/epistemologia_feminista.pdf>. Acesso em: 15 jan. 2015.

ROSADO-NUNES, Maria José F. Gênero, saber, poder e religião. In: ANJOS, Márcio Fabri dos (Org.). Teologia e novos paradigmas. São Paulo: Loyola, 1996.

RUBIN, Gayle. El tráfico de mujeres: notas sobre la "economia política” del sexo. Nueva Antropología, México, v. VIII, n. 30, 1986.

SARDENBERG, Cecilia Maria Bacellar. Da Crítica Feminista à Ciência a uma Ciência Feminista? Labrys. Estudos Feministas (Online), v. 11, p. 45, 2007. Disponível em: < https://repositorio.ufba.br/ri/bitstream/ri/6875/1/Vers\%C3\%A3

o\%20FInal\%20Da\%20Cr\%C3\%ADtica\%20Feminista.pdf>. Acesso em: 2 jul. 2014.

SCHIEBINGER, Londa. O feminismo mudou a ciência? Bauru: EDUSC, 2001.

SCOTT, Joan. Gender: a useful category of historical analyses. Gender and the politics of history. New York: Columbia University Press, 1989. Disponível em: <http://facultypages.morris.umn.edu/ deanej/

UMM\%20Home\%20Page/2001/Readings/Gender/Scott_Useful\%2oCategory.pdf>. Acesso em: 30 abr. 2014. 